
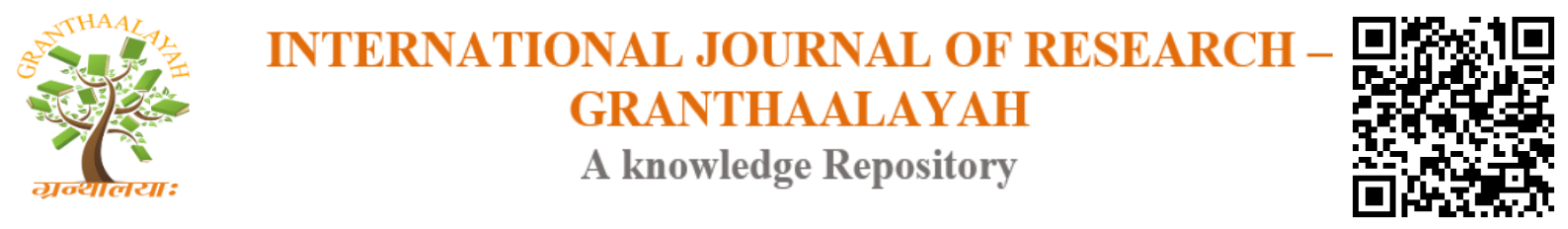

Management

\title{
ACCESS TO COMMUNICATION PLANNING AND TRANSPORTATION MANAGEMENT TECHNOLOGY IN ASSESSMENT OF VEHICLE OPERATIONS IN PEKANBARU CITY'S, RIAU, INDONESIA
}

\author{
Hefri Yodiansyah ${ }^{* 1}$, Nanik Yuzalmi ${ }^{2}$, Irsyadi Zain ${ }^{3}$ \\ ${ }^{* 1}$ Department of Communication Science, Persada Bunda College of Social and Political \\ Sciences (STISIP PERSADA BUNDA), Pekanbaru cities, Indonesia \\ ${ }^{2}$ Company Management Study Program, Secretarial Academy and Persada Bunda Management \\ (ASM PERSADA BUNDA), Pekanbaru cities, Indonesia \\ ${ }^{3}$ Production Management Study Program, Secretarial Academy and Persada Bunda Management \\ (ASM PERSADA BUNDA), Pekanbaru cities, Indonesia
}

\begin{abstract}
Management of leasing vehicles contributes significantly to amount of transportation driving the supply of fiduciaries fiduciary progress on the streets in Pekanbaru cities, Indonesian state. This development was caused by poor public transport supplies, urban leasing vehicles with fiduciary patterns and poor roads. The use of fiduciary vehicles for public transport in the city of Pekanbaru, Riau, Indonesia is associated with a high level of accidents both on the side of drivers, drivers and passenger's fiduciary vehicles. This study investigates the social-economic impact of Pekanbaru city's most likely drivers in the Regional Government areas Indonesian state. Questionnaires were given to samples randomly selected 200 users' area. Of the 200 questionnaires given, 183 questionnaires were received for analysis using the Statistical Package for Social Sciences (SPSS). The findings show that the majority of commercial fiduciary riders are adults between the ages of 31 and 40 years. Most (72.9\%) are married and have sufficient educations. Selected male sexes, $78.6 \%$ of the 66 respondents Company guarantees full-time fiduciary vehicles and has operated for more than four years with a general policy pattern. The majority of riders are involved in business because of the urgent need to survive and defend their families. In addition, most motorists do not take the necessary precautions, they are earning consumers and family management even during working hours and this reason has been identified as the main cause of their carelessness.
\end{abstract}

Keywords: Access; Company; Driver; Passenger; Public Transportation.

Cite This Article: Hefri Yodiansyah, Nanik Yuzalmi, and Irsyadi Zain. (2018). "ACCESS TO COMMUNICATION PLANNING AND TRANSPORTATION MANAGEMENT TECHNOLOGY IN ASSESSMENT OF VEHICLE OPERATIONS IN PEKANBARU CITY'S, RIAU, INDONESIA." International Journal of Research - Granthaalayah, 6(9), 1-16. https://doi.org/10.5281/zenodo.1435199. 


\section{Introduction}

Transport is an important element in economic development and it affords the social and political interaction that most people take for granted [4]. The provision of transport infrastructure has grown extensively across the globe through a range of networks of modes which have undergone technological improvements cutting across the motive power, the tracks as well as the means which serve as compartment for passengers and goods. It is also a key player in the transfer and distribution of goods from the input points through the manu factoring line to the customers [3]. Perhaps, this led to the assertion by [6], that there is no escape from transport since it's a key stone of civilization. In Indonesian, road transport is the dominant mode of movement for both freight and passenger traffic [29]. The impact of the railway has been dwindling and it eventually collapses about a decade ago. The introduction of motorcycle popularly called 'SCCT' System as an alternative mode of transport in urban centre's was prompted by the high cost and inevitable transport service provision which impacted negatively on economic activities and mobility of the urban populace. Of particular interest is the fact that increasing demand for public transport has not been able to match the level of provision of transport services. The situation is also worsened by the increasing level of poverty of urban residents in Indonesian state [5]. The uses of motorcycles for urban transportation are not a new phenomenon in Indonesian. It has been commonly used as intra-city and inter-city urban and rural transport services in revering areas of the country for over three decades [24].

\section{Statement of Research Problem}

The rapid rate of urbanization in Indonesian has become an issue of serious concern to policy makers in the various sectors including transport. Meeting transportation needs of man is the most difficult challenge of every environment. The situation becomes compounded with the increasing wave of human concentration in urban centres, leading to scrupulous and unorganized land use activities. Perhaps, one of the most important steps towards the realization of better urban transportation system for Indonesian urban centres is the effective management and coordination of motorcycle passenger transport services. The association of motorcycle operators must be reorganized to provide basis for dialogue and coordination. This must be supported by central legislation to regulate their operations at various level of governance in the country particularly at state and federal levels. However, the operations of motorcycles are without entry and quality controls, including safety. [2] Point to the fact that riders' (operators) training and safety precautions are grossly inadequate or completely ignored. There is also lack of delineated transport infrastructure for this mode thus leading to motorcycle-motor vehicle-pedestrian struggle for road space. The resultant effect is high incidence of road accidents involving motor cyclists/passengers. In the past, most states made attempt to ban this mode of public transport services but its role has now become inevitable, because of inadequate public urban transport supply, as the operators are issued with riders licenses and hackney permits thus legalizing this mode surreptitiously. Invariably, national economic development policies should be designed in such that they can stimulate broad range of urban employment opportunities that are labour intensive coupled with the capacity to encourage effective utilization of natural and human resources. In the last two decades mobility and accessibility problems appear to have been the main challenges facing Indonesia and her cities in the country's desire for development. In cities where transportation problems are acute and concentrated, achieving a maximum level of urban mobility is seen as a very crucial ingredient for the enhancement of the standard of living of inhabitants and the 
economic base of the urban centers [12]. The foregoing makes it imperative to appraise the use of motorcycles as a mode of public transport and examine the operational modalities, the perception of the residents of Pekanbaru cities, especially the users, the constraints and benefits; then proffer measures for alleviating the identified problems/deficiencies. Literature Review The transport sector is the mover of the Indonesia economy and indeed of any economy [23]. The importance of mobility to a nation's economic base cannot be overemphasized. Specifically, transport is central to the developmental process of a health economy and societal growth. This is due to the fact that transport influences and is influenced by other sectors that make up, not only the total urban system, but the entire human settlements as well. Indonesian has been branded a country with an unenviable record of road traffic accidents [16] in the world the contribution of road transport [17] to the Gross Domestic product of the country [21] has been adversely affected as a result of losses suffered from road traffic accidents and its attendant loss [19] of property and human life [26]. The government's inability to provide conventional mode of transport has necessitated use of motorcycles and tricycles to move people, goods and services from one point to another under conditions considered to be unsafe and accident-prone [11]. In many area growth cities, transport situation has reached a crisis point [27]; the consequence of several years of neglect by succeeding administration [22]. Hence, there is nothing novel in stating that transportation in Pekanbaru cities is grossly inadequate [13]. Over three quarter of the households in most Indonesia cities earn income below poverty lines [7]. This has affected the rate of procedure of new vehicles, and it is obvious that this trend with the inevitable declining level of existing purchasing power has taken its toll on the mobility needs in Indonesian state [28]. In the last decade, most people in urban areas have depended heavily on motorcycle as a means of transport [15]. Two major issues which have dominated the development and growth of urban centre's in Indonesian in the past two decades are the rapid rate of growth of the urban population and widening gap between transport demand and supply [14]. The inability to provide adequate motor vehicles for urban mobility has been responsible for the influx of used motorcycles for urban public transport into cities in Indonesian. Some factors are also responsible for the emergence of this mode for public transport in the country. Some of these factors include: the poor economy; high rate of inflation which led to exorbitant prices of spare parts, as well as high rate of unemployment which compelled many people to seek other means of sustaining their livelihood. In Pekanbaru cities in the contribution of motorcycles to the total kilometer age travelled has increased over the years. By coincidence, the level of danger portends by its usage is also quite enormous judging from the wave of losses suffered as a result of accident arising from the conflict between motor vehicles and motorcycles in most urban centre's in the country [18]. The share of motorcycle in the total number of trips made in most urban centres in the world is quite substantial particularly for low income households. Further investigations indicate that the patronage of this service (commercial motorcyclists) cuts across all social status as most people will opt for it with the hope of reducing the wear and tear of their private vehicles which will in the long term become more expensive to maintain [8]. [9] Observed that motorcycles contribute significantly to the number of automobile on the roads in Indonesian. This development is attributable to poor public transport supply, urban sprawl and bad roads. The use of motorcycles in Indonesian State is associated with high accident rate both on the side of the riders and the passengers. Passengers, both the rich and poor, use motorcycles purposely to beat traffic congestion, save time band enhance accessibility [20]. Following [1] also observed that government inability to provide conventional mode of transport has necessitated use of motorcycles and tricycles to move people, goods and services from one point to another under conditions considered to be unsafe and accident-prone. The attended neglect 
and gaps in Indonesia's road traffic safety administration are great and are responsible for the high rate of traffic accidents. A chaotic situation has arisen from this unhealthy development. The major stumbling block has been identified as human factors. The problems include motorist driving culture, poor attitudinal and incompetence of many professional drivers and wide extensive indiscipline, corruption, enforcement, disobedience for law, institution gridlocks characterizing the motoring behavior. Hence, a well - founded and integrated road safety and behavioral education will serve as succor for this. [2] Since, no matter the sophistication level of engineering ingenuity could resolve the problem except an integrated traffic education, attitudinal change, persuasion, reorientation and modification of drivers and road users' minds and character. Over the years, commercial motorcycle operators have organized themselves into various unions at the state and national level [30]. It is compulsory for anyone willing to operate as a commercial motorcyclist to register with any of the affiliated associations of the transport unions.

\section{Literature Review}

The previous research as an example of communication planning and transportation management technology in the assessment of regional vehicle operations. With the SCCT System method on the role and pattern of a vehicle operating system assessment of transportation areas. The Future of Communication Research in Corporate Reputation Studies, along Craig E. Carrollin in New York University, USA In graduate school seminars devoted to communication research and theory students are often told the story about the six blind men and the elephant-but do you know the story about the six blind elephants and the man? Six blind elephants were discussing what humans were like. After arguing among themselves, they decided to find a human and determine what he or she was like by direct experience. The first blind elephant found a man and after touching him thoroughly with his feet declared, "Humans are flat." The other blind elephants took turns touching the man the same way, and they all agreed. To some degree, this inverted story of the blind men and the elephant illustrates what has occurred over the past twenty years incorporate reputation scholarship. Across academic disciplines, including the field of communication, scholars privately delight in the wide variety of definitions and ways of measuring reputation. As long as there is agreement that the verdict is out, there is room, time, and need for further debate and study. Nevertheless, we have another elephant in the room. It concerns our taken-for-granted consensus on the reasons for studying corporate reputation and the benefits for organizations of investing in reputation management. It also concerns our preference for particular theories and academic disciplines for studying corporate reputation, the incontestable nature of what counts as a reputation attribute, and our delimitation of inquiries in terms of antecedents, dimensions, and consequences. The inversion of the story about blind men and elephants points to the dangers of establishing authoritative descriptions or definitions and then rushing to judgment too soon. We may draw premature conclusions that are not very satisfying, kill the subject of interest in the process, and fail to learn what we need to know. With premature assessments that are unsatisfying, empirical results that are anticlimactic, and a subject of interest that is dead, we may conclude that further study is not warranted. But if our subject were given time and voice to speak, we might discover that the most interesting questions, stories, contexts, and applications have yet to be revealed. Such are the possibilities of studying corporate reputation from a communication standpoint. 
The following communication planned in addition contextual supports and barriers to career choice: asocial cognitive analysis report for a team researching by Robert W. Lentfrom University of Maryland, it's he is name Steven D. Brown Loyola from University Chicago and named recipient Gail Hackett from Arizona State University, following is about social cognitive career theory (SCCT; R. W. Lent, S. D. Brown, \& G. Hackett, 1994)emphasizes cognitive-person variables that enable people to influence their own career development, as well as extra-person (e.g., contextual) variables that enhance or constrain personal agency. Although the theory has yielded a steady stream of inquiry and practical applications, relatively little of this works has examined SCCT's contextual variables or hypotheses. In this article, several avenues for stimulating study of the contextual aspects of career behavior are considered. In particular, the authors (a) examine "career barriers," a conceptually relevant construct, from the perspective of SCCT; (b) advocate study of contextual supports as well as barriers; and (c) propose additional context-focused research and practice directions derived from SCCT.

The communicative constitution of adaptive capacity during Sweden's by Jody L.S. Jahn University of Colorado, Boulder, Colorado, USA, and Catrin Johansson Department of Media and Communication, Mid Sweden University, Sundsvall, Sweden of this paper is purpose to explain how adaptive capacity is accomplished through communication processes and can contribute to enhancing disaster resilience. The authors adopt a structurational "four flows" explanation of the communication processes. In addition to methodology approach - The observed and analyzed discourse in meetings of a crisis communication network consisting of representatives of municipalities and public authorities involved in crisis communication management during the Västmanland wildfire in Sweden. It's findings of adaptive capacity during the wildfire was principally accomplished through the structurational communication processes or "flows" of selfstructuring, activity coordination, and institutional positioning. These flows intersected demonstrating how communication accomplishes the development of a responsive affiliation, organizes stabilizing structuring practices, and enables adaptive structuring practices. In studies is a communicative explanation for adaptive capacity, which draws from a structurational model of constitutive communication, and lends further understanding to improvisation during disasters. On our discuss the findings in relation to improvisation, suggesting how the findings can inform future coordinated crisis communication for the public and news media. The recommendations address how practitioners might build a responsive affiliation, use minimal structures (e.g. communication practices), and maintain flexibility by introducing group reflexivity behaviors. The value -The system management provide new theoretical and empirical knowledge of the communicative constitution of adaptive capacity during a disaster. In during thus is an, Resilience, Adaptive capacity, communicative constitution of organization, Four flows CCO paper type research paper works for its a networks, multiplexity, friendship networks, emergency management networks. The transportation management technology with the understanding multiplexity of collaborative emergency management networks by he is name Qian Hu, then there's American review of public administrations is articles explores the multiplex relationships among organizations within the context of emergency management. It examines the role of friendship networks and disaster preparedness networks in predicting sustainable collaborative disaster response networks. Furthermore, it examines the impact of emergency management systems on network building and sustainability. This article applies inferential network analysis methods in analyzing relationships among emergency management networks and examines the predictive power of reestablished network arrangements. This research suggests that friendship networks are important for 
encouraging organizations to be involved in disaster preparedness networks. Yet it is the collaboration ties during disaster preparedness that influence the formation of collaborations during disaster response. Structural attributes of emergency management systems have been impacts on the development of multiplex relationships among organizations within various networks. These findings not only contribute to developing sustainable emergency management networks but also provide insights for building collaborative networks in a broader context. Be careful with their own a said work's is a networks, multiplicity, friendship networks, and emergency management networks. On assessment of regional vehicle operations in there are main conditions for integration success with a lot is delegation of theories on communication planning and transportation management technology in the assessment of regional vehicle operations.

\section{Materials and Methods}

This research is descriptive survey on an assessment of motorcycle operation in Pekanbaru city's areas of Riau Indonesian state. The data was generated using the research instrument that was adopted for the study. The researcher constructed questionnaires that sought the opinion of the operators and user of motorcycle in Pekanbaru city's Indonesian state history. The number of questionnaire that was used for the analysis was 84 for the riders while the users of the motorcycle made up 183 respondents used for the research in that category.

Analysis of Responses.

Table 1: Age of motorcycle rider.

\begin{tabular}{|l|l|l|l|}
\hline & & Frequency & Percent \\
\hline Valid & $18-30$ years & 26 & 31.0 \\
\hline & $31-40$ years & 36 & 42.9 \\
\hline & $41-50$ years & 12 & 14.3 \\
\hline & 51 - 60 years & 10 & 11.9 \\
\hline & Total & $\mathbf{8 4}$ & $\mathbf{1 0 0 . 0}$ \\
\hline
\end{tabular}

Source: Fieldwork, July 2017.

From the data collated on the operators of motorcycle used for the study, it was observed that $31 \%$ of them are of ages less than 18 years, $42.9 \%$ of said are of ages that span between $31-40$ years, $14.3 \%$ indicated their ages to be between $41-50$ years while the remaining $11.9 \%$ are of the ages between $11.9 \%$. This goes to shows that most of the operators of motorcycle in this area are mostly people in their prime that have no other source of income or form of employment and as such have resorted to the use of the motorcycle to make a living.

Table 2: Marital status of rider.

\begin{tabular}{|l|l|l|l|}
\hline & & Frequency & Percent \\
\hline Valid & No response & 8 & 9.5 \\
\hline & Married & 61 & 72.6 \\
\hline & Single & 15 & 17.9 \\
\hline & Total & $\mathbf{8 4}$ & $\mathbf{1 0 0 . 0}$ \\
\hline
\end{tabular}

Source: Fieldwork, July 2017. 
Out of the 84 operators of motorcycle used for the research, it was observed that $9.5 \%$ of them did not indicate their marital status, $72.6 \%$ of them are married while the remaining $17.9 \%$ are single. This result shows that marital status does not serve as hindrance for people who intend to take up motorcycle riding in Pekanbaru city's most Indonesian state.

Table 3: Educational qualification of rider of Communication standpoint

\begin{tabular}{|l|l|l|l|}
\hline & & Frequency & Percent \\
\hline Valid & No response & 3 & 3.6 \\
\hline & Primary education & 28 & 33.3 \\
\hline & Secondary education & 47 & 56.0 \\
\hline & ND / NCE & 3 & 3.6 \\
\hline & HND / BSC & 3 & 3.6 \\
\hline & Total & $\mathbf{8 4}$ & $\mathbf{1 0 0 . 0}$ \\
\hline
\end{tabular}

Source: Fieldwork, July 2017.

The evidence from the above table shows that the majority of motorcycle operators in Pekanbaru cities have secondary school level of education, accounting for $56 \%$ of the sample, $33.3 \%$ of them have primary education, though $3.6 \%$ of them did not indicate their level of education but the remaining respondents have some form of tertiary education. This reveals that more of the operators have secondary school education at the most, this could explain the nonchalant attitude that is displayed by the riders when issues that concern their safety is concerned hence the need for adequate awareness campaign for operators in Indonesian state.

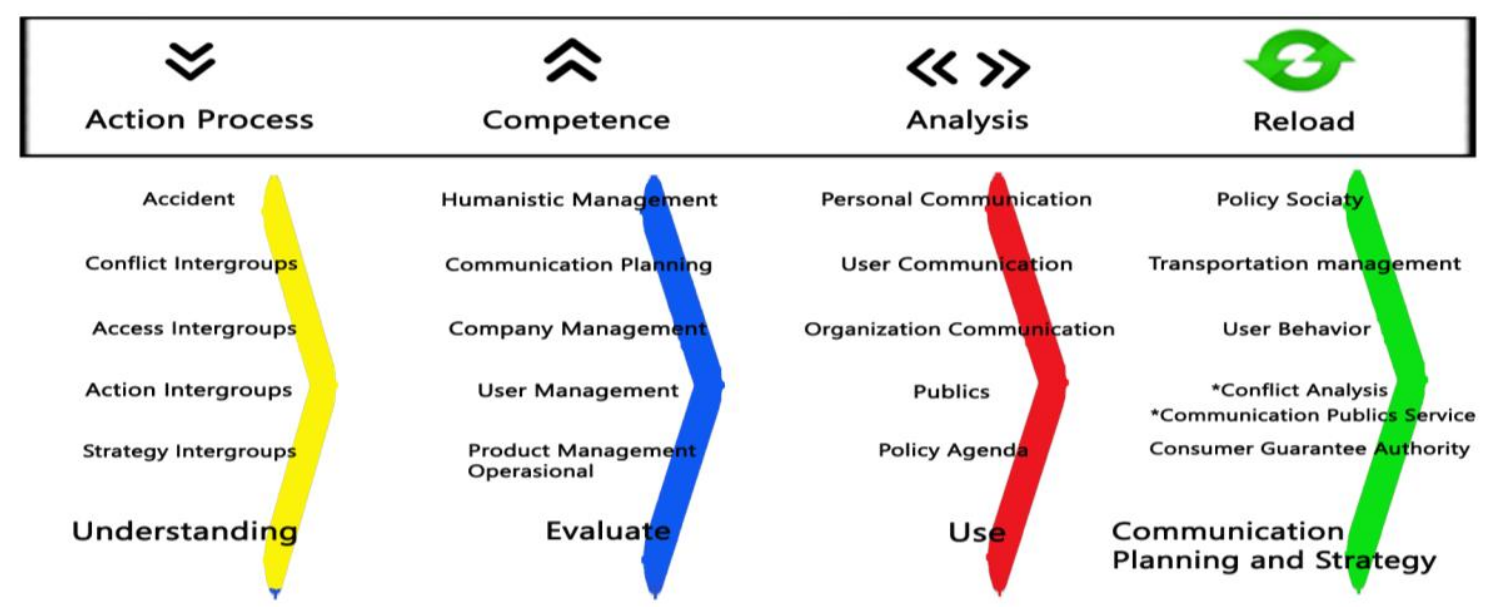

Figure 1: Perseption of the analyzee human communication areas.

Source: Fieldwork, July 2017.

Perseption of the analyzee human communication areas in subtance topics of the sub-themes were presented to the care providers and revised with consideration to their opinion. The remaining eight observational notes were analysed. A co-researcher read one-third of the observational notes and the thematisation. A process of reflection and discussion resulted in agreement on a set of subthemes. Lastly, reflection on the sub-themes and a review of literature related to the sub-themes provided phenomena that seemed to serve as relevant headings to unify the sub-themes into themes. To reveal meaning units that rejected interpretations of the observational text the reflective 
dialogues were analysed and nothing that contradicted the themes could be found. The first question concerning credibility arises when making a decision about the focus of the study, selection of context, participants and approach to gathering data. Choosing participants with various experiences increases the possibility of shedding light on the research question from a variety of aspects. In our illustrations, interviewees' various genders and ages, and observers with various perspectives, contributed to a richer variation of the phenomena under study. Selecting the most appropriate method for data collection and the amount of data are also important in establishing credibility. The amount of data necessary to answer a research question in a credible way varies depending on the complexity of the phenomena under study and the data quality.

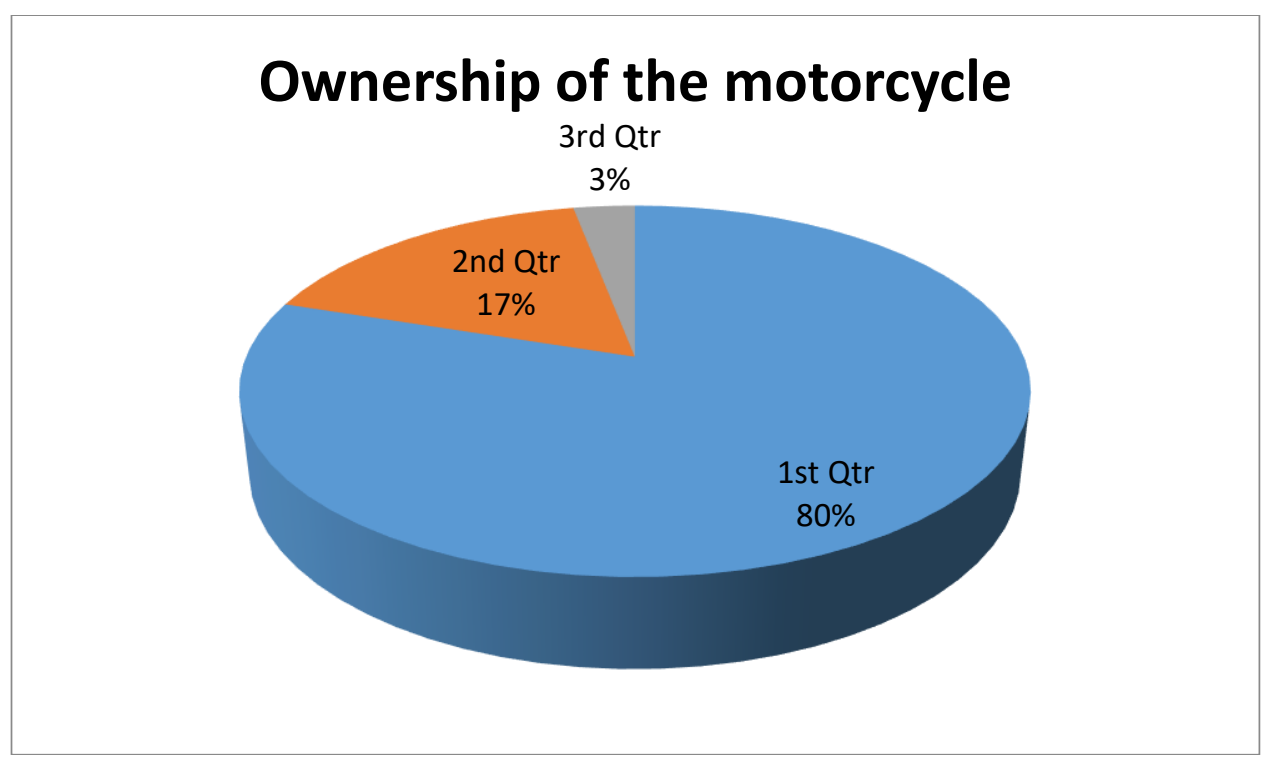

Figure 2: Ownership of the motorcycle.

Source: Fieldwork, July 2017.

In the social construction and constitutive views with the ownership used for business. In terms of the ownership of the motorcycle been used for business, it was observed that $80 \%$ of the respondents said the bike belongs to them while $17 \%$ revealed that the bike they use is not theirs, though there is a $3 \%$ of the sample that did not reveal any information on the ownership of the motorcycle with a components them users.

As the components with an access to communication planning and the transportation technology management in a assessing vehicle operations, such as:

1) Access

- Understand

- Learn

- Use

- Operational communication strategies of beat traffic congestion, save time band enhance accessibility

2) Company

- Access

- Action 
- Target

- Outcome

3) Driver

- Transport services

- Transport areas

- Communication commercial

- Communication stockpoint

4) Passenger

- Drivers and road users' minds and character.

- Commercial motorcycle operators have organized themselves.

- Associations of the transport unions.

- Corporate reputation studies of drivers and road users' with professional drivers.

5) Public transportation

- Human factors public transportation

- Many people have been forced from conflict between motorized vehicles that cut all social status.

- Deliberately to beat traffic congestion inability to provide conventional.

- Driving the culture of many professional drivers and wide broad indiscipline, corruption, law enforcement, non-compliance with the law, institutional bottlenecks that characterize motorbike behavior.

- The inability of the government to provide a conventional moodle attitude.

\section{Results and Discussions}

In a provide a conventional moodle attitude in registered commercial motorcycles operator with a registered commercial, act:

Table 4: Are you a registered commercial motorcycles operator.

\begin{tabular}{|l|l|l|l|}
\hline & & Frequency & Percent \\
\hline Valid & Behavior response (yes) views & 73 & 86.9 \\
\hline & Behavior response (no) views & 11 & 13.1 \\
\hline & Total & $\mathbf{8 4}$ & $\mathbf{1 0 0 . 0}$ \\
\hline
\end{tabular}

Source: Fieldwork, July 2017.

The above table reveals that the level of enforcement for the operators of motorcycle to register is highly functional in Indonesian state, as $86.9 \%$ of the respondents are registered commercial motorcycle operators while the remaining $13.1 \%$ are not registered. 


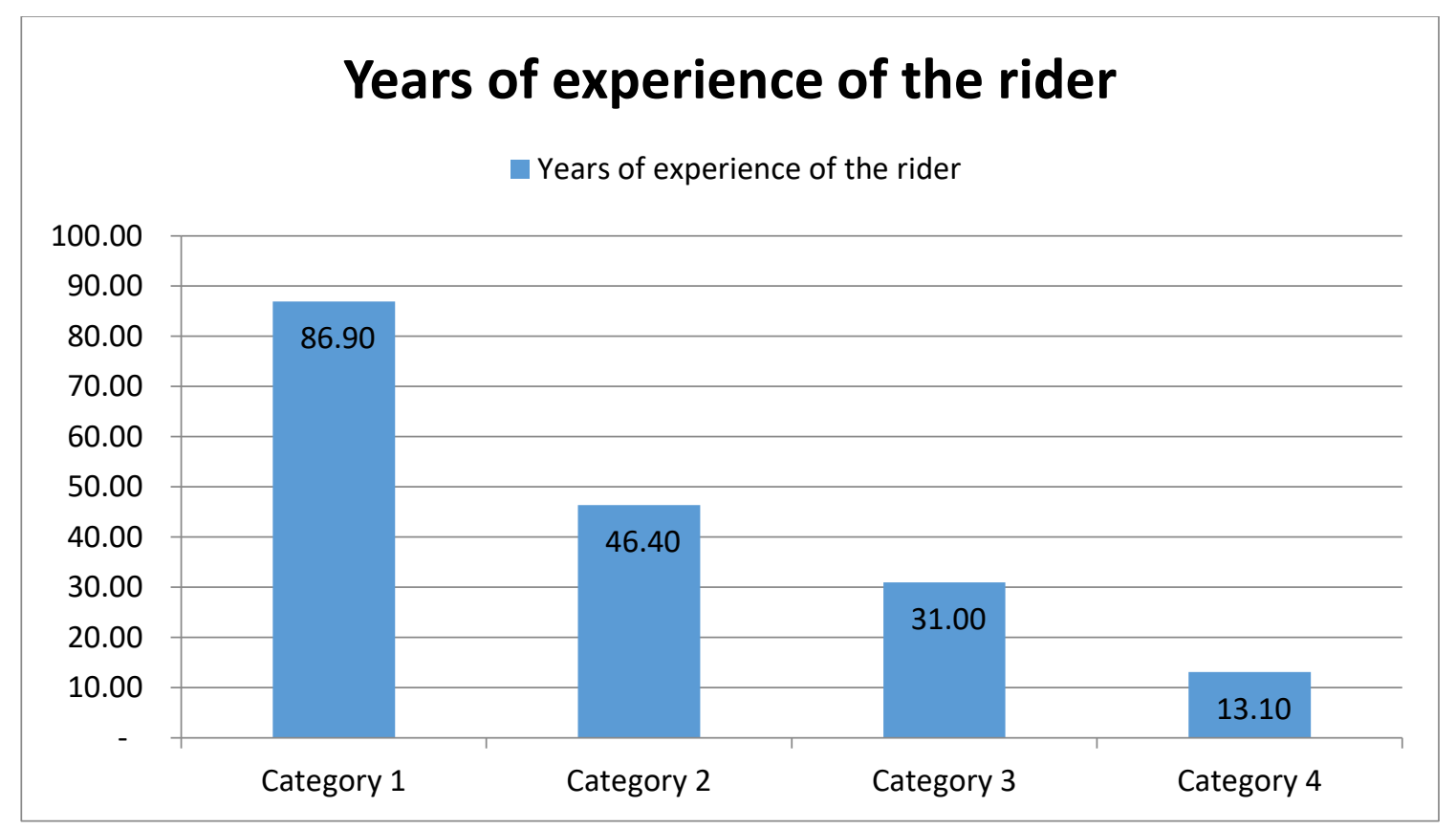

Source: Fieldwork, July 2017.

Figure 2: Years of experience of the rider.

The table above shows that $31 \%$ of the respondents have been on this job for a maximum of 3 years, $46.4 \%$ of them said they have been involved in the business for between $4-8$ years while the remaining $22.6 \%$ said they have been operating motorcycle in Pekanbaru city's most Indonesian state for more than 8 years.

Table 5: Riders' involvement in serious accident since operation of motorcycle business of Personal agency.

\begin{tabular}{|l|l|l|l|}
\hline & & Frequency & Percent \\
\hline Valid & Behavior response studies (yes) views & 46 & 54.8 \\
\hline & Behavior response studies (no) views & 38 & 45.2 \\
\hline & Total & $\mathbf{8 4}$ & $\mathbf{1 0 0 . 0}$ \\
\hline
\end{tabular}

Source: Fieldwork, July 2017.

Out of the sample for the study, $54.8 \%$ said they have been involved in accidents since they started the business while the remaining $45.2 \%$ said they have never been involved in motorcycle accidents.

Table 6: Daily income of Responsive affiliation organization.

\begin{tabular}{|l|l|l|l|}
\hline & & Frequency & Percent \\
\hline Valid & Less than Rp. 1.500.000 & 27 & 32.14 \\
\hline & Rp. 1.500.000-Rp. 3.000.000 & 43 & 51.19 \\
\hline & More than Rp. 3.000.000 & 14 & 16.67 \\
\hline & Total & $\mathbf{8 4}$ & $\mathbf{1 0 0 . 0}$ \\
\hline
\end{tabular}

Source: Fieldwork, July 2017. 
The table shows that $32.14 \%$ of the riders earn less than Rp. 1.500 .000 income, while $51.19 \%$ of them said the daily income is between Rp. 1.500.000 - Rp. 3.000.000 income, ore than Rp. 3.000 .000 income and they account for $16.67 \%$ of the sample.

Table 7: Motivation of rider to the occupation of organizes stabilizing structuring practices.

Source: Fieldwork, July 2017.

\begin{tabular}{|l|l|l|l|}
\hline & & Frequency & Percent \\
\hline Valid & The income & 34 & 40.5 \\
\hline & No better Alternative & 50 & 59.5 \\
\hline & Total & $\mathbf{8 4}$ & $\mathbf{1 0 0 . 0}$ \\
\hline
\end{tabular}

Evidence from the above table shows that $40.5 \%$ of the riders said they are motivated to go into the motorcycle business because of the income that they derive while the remaining $59.5 \%$ said they are motivated to the job because there is no better alternative.

Table 8: Gender of the User of Motorcycle operators.

Source: Fieldwork, July 2017.

\begin{tabular}{|l|l|l|l|}
\hline & & Frequency & Percent \\
\hline Valid & Male & 116 & 63.4 \\
\hline & Female & 67 & 36.6 \\
\hline & Total & 183 & $\mathbf{1 0 0 . 0}$ \\
\hline
\end{tabular}

After collating the data generated from the survey on users of motorcycle, it was discovered that $63.4 \%$ of the users of motorcycle in Pekanbaru city's most people Indonesian state are males while the remaining $36.6 \%$ are females.

Source: Fieldwork, July 2017.

Table 9: Age of the respondent.

\begin{tabular}{|l|l|l|l|}
\hline & & Frequency & Percent \\
\hline Valid & Below 18 years & 11 & 6.0 \\
\hline & $18-30$ years & 69 & 37.7 \\
\hline & $30-40$ years & 51 & 27.9 \\
\hline & $40-50$ years & 36 & 19.7 \\
\hline & $50-60$ years & 12 & 6.6 \\
\hline & Above 60 years & 4 & 2.2 \\
\hline & Total & 183 & $\mathbf{1 0 0 . 0}$ \\
\hline
\end{tabular}

In terms of the age of the user of motorcycle in Indonesian state, it was observed that $6 \%$ of them are of ages less than 18 years, $37.7 \%$ are of the ages between $18-30$ years, $27.9 \%$ are of the ages between $30-40$ years, the age range of $19.7 \%$ of them is $40-50$ years, $6.6 \%$ said their ages is between $50-60$ years while the remaining $2.2 \%$ said they are more than 60 years. 
Table 10: Reasons for patronizing motorcycle operators.

\begin{tabular}{|l|l|l|l|}
\hline & & Frequency & Percent \\
\hline Valid & No response & 16 & 8.7 \\
\hline & Cheapness or affordability & 16 & 8.7 \\
\hline & Comfort & 7 & 3.8 \\
\hline & Reliability & 10 & 5.5 \\
\hline & Reduced waiting time & 106 & 57.9 \\
\hline & No alternative means & 28 & 15.3 \\
\hline & Total & 183 & $\mathbf{1 0 0 . 0}$ \\
\hline
\end{tabular}

Source: Fieldwork, July 2017.

The reason for patronizing the motorcycle operators is shown in the table above, it reveals that $8.7 \%$ of the sample did not answer, $8.7 \%$ said it is because it is affordable, the comfort is given as a reason for patronage by $3.8 \%, 5.5 \%$ said the reason is it reliability, a majority of the sample said the reason is that it reduces waiting time while the remaining $15.3 \%$ said it's because there is no other alternative means of transportation.

Table 11: Purpose for using motorcycle as a mode of transportation.

\begin{tabular}{|l|l|l|l|}
\hline & & Frequency & Percent \\
\hline Valid & No response & 16 & 8.7 \\
\hline & School & 21 & 11.5 \\
\hline & Work & 117 & 63.9 \\
\hline & Social activities & 9 & 4.9 \\
\hline & Others & 20 & 10.9 \\
\hline & Total & 183 & $\mathbf{1 0 0 . 0}$ \\
\hline
\end{tabular}

Source: Fieldwork, July 2017.

On collation of results, it was discovered that $63.9 \%$ of the users of motorcycle operators use it for the purpose of going to work, $11.5 \%$ said it is used when going to school, only $4.9 \%$ of the sample use it for social activities, $8.7 \%$ of the sample did not answer the question while the remaining $10.9 \%$ said it is used for other purposes only for users.

Table 12: Users involvement in motorcycle accidents.

\begin{tabular}{|l|l|l|l|}
\hline & & Frequency & Percent \\
\hline Valid & No response & 3 & 1.6 \\
\hline & (Yes) accidents & 35 & 19.1 \\
\hline & (No) accidents & 145 & 79.2 \\
\hline & Total & 183 & $\mathbf{1 0 0 . 0}$ \\
\hline
\end{tabular}

Source: Fieldwork, July 2017.

In terms of involvement in accidents, the table reveals that $79.2 \%$ of the respondents said they have never been involved in motorcycle accident, $19.1 \%$ said they have been involved in motorcycle accidents, though $1.6 \%$ did not answer the question. 
Table 13: Users' assessment of the quality of service provided in enables adaptive structuring practices.

Source: Fieldwork, July 2017.

\begin{tabular}{|l|l|l|l|}
\hline & & Frequency & Percent \\
\hline Valid & Good & 32 & 17.5 \\
\hline & Poor & 51 & 27.9 \\
\hline & Highly Risky & 96 & 79.2 \\
\hline & Below expectation & 4 & 2.2 \\
\hline & Total & 183 & $\mathbf{1 0 0 . 0}$ \\
\hline
\end{tabular}

In terms of the quality of service that the motorcycle operators provide, it was observed that $17.5 \%$ of them ranked the quality as Good, $27.9 \%$ of them said the quality level is poor, $52.5 \%$ of the users see the level of quality as highly risky while the remaining $2.2 \%$ said it is below expectation. The results quality section should provide details of all of the experiments that are required to support the conclusions of the paper. The section may be divided into subsections, each with a concise subheading.

It is advised that this section be written in past tense. It is a good idea to rely on charts, graphs, and tables to present the information. This way, the author is not tempted to discuss any conclusions derived from the study. The charts, graphs, and table should be clearly labeled and should include captions that outline the results without drawing any conclusions. A description of statistical tests as it relates to the results should be included.

\section{Conclusions and Recommendations}

Summarize the results in words rather than numbers and elaborate on the extent to which the objectives of the study One of the most important steps towards the realization of better urban transportation system for Pekanbaru city's urban centers is the effective management and coordination of motorcycle passenger transport services. National economic development policies should be designed such that they can stimulate broad range of urban employment opportunities that are labour intensive coupled with the capacity to encourage effective utilization of natural and human resources. In some areas where buses are completely absent, efforts should be made to encourage the use of tricycle which provides more protection than motorcycles. If the motorcycle as a mode of public transport must exist, adequate infrastructure facilities in addition to through screening of the motorcycles for road worthiness and testing of the operators for efficiency, standardization of motorcycle to be used among others should be done. The cost of providing this will no doubt be higher than the cost of adding a few buses to the existing ones to alleviate the problems of commuters and mitigate the incessant road carnage occasioned by motorcycles.

This section may also include also include discussion on theoretical and methodological implications of findings. The public transportation of human factors public transportation a many people have been forced from conflict between motorized vehicles that cut all social status in human research. The deliberately to beat traffic congestion inability to provide conventional. A driving the culture of many professional drivers and wide broad indiscipline, corruption, law enforcement, non-compliance with the law, institutional bottlenecks that characterize motorbike behavior. In the inability of the government to provide a conventional moodle attitude. 
On include information from a literature search focus on the primary conclusions of the study human communication playing management Interpret the results for the audience; at the components with an access to communication planning and the transportation technology management in a assessing vehicle operations, (1) Access: understand; learn; use; and operational communication strategies of beat traffic congestion, save time band enhance accessibility, (2) Company: access; action; target; and outcome, (3) Driver: transport services; transport areas; communication commercial; communication stock point, (4) Passengers: drivers and road users' minds and character; commercial motorcycle operators have organized themselves; associations of the transport unions; corporate reputation studies of drivers and road users' with professional drivers, and (5) Public transportation: human factors public transportation; many people have been forced from conflict between motorized vehicles that cut all social status; deliberately to beat traffic congestion inability to provide conventional; driving the culture of many professional drivers and wide broad indiscipline, corruption, law enforcement, non-compliance with the law, institutional bottlenecks that characterize motorcycle behavior; and the inability of the government to provide a conventional moodle attitude. On the results of problems that cannot be explained from scientific writing management solutions to interpretation with scientific goals.

Be sure to avoid over-interpreting the results and make general conclusions that cannot be justifiably derived from the parameters of the studies human management Communication in factors public transportation a many people have been forced from conflict between motorized vehicles that cut all social status quo.

Discuss any implications and limitations of the study as well as to what extent the conclusions are in concert with other, act; access, company, driver, passenger, public transportation researchers. The main results should be presented clearly and briefly, insisting on their significance and degree of novelty. On include information from a literature search focus on the primary conclusions of the study human communication playing management Interpret the results for the social audience sociaty.

\section{Acknowledgements}

The objective in this study examines the use of the motorcycle as a mode of public passenger transport, through the study of the operators, users, and the efficiency or otherwise of this mode. The result so far indicates that the adverse economic situation of the country has forced the operators into this business, and not the interest of meeting the demand created by in adequate transport facilities. On the other hand, the users are constrained to use this mode in the absence of alternatives. The study also shows with reasons that the motorcycle is not in any way a mode to be used for intra-urban public transport. A driving the culture of many professional drivers and wide broad indiscipline, corruption, law enforcement, non-compliance with the law, institutional bottlenecks that characterize motorbike behavior. In the inability of the government to provide a conventional moodle attitude. The public transportation of human factors public transportation a many people have been forced from conflict between motorized vehicles that cut all social status quo. The People who contributed to the work but do not fit criteria access, company, driver, passenger, public transportation researchers for authorship should be listed, along with their contributions access to communication planning and transportation management technology in assessment of vehicle operations. Funding sources that have supported the work should also be 
cited It is advised that authors ensure that anyone named in the assessment of vehicle operations agrees to being as an access to communication planning and transportation management with technology assessment.

\section{References}

[1] Adesanya Soji (1998) "The use of motorcycle for public transport" NISER Monograph Series No. 6. 1998, NISER, Ibadan.

[2] Adesanya, A (2004), Analysis and Management of Transport Sector Performance and Its Intersectoral Linkages. A paper Presented at the Training Programme on Sectoral Policy Analysis and Management, Ibadan, June 21-July 9, 2004.

[3] Badejo, B. A (2002): The dilemma of emerging urban public transportation in Nigeria. Lasu Journal of Social Science Vol. 4.

[4] Button K. J and Hensher (2001) eds. Handbook of Transport Systems and Traffic Control, Pergamon United Kingdom.

[5] Carrollin, Craig E. The Future of Communication Research in Corporate Reputation Studies, New York University, USA.

[6] Doerfel, Marya L. and Barnett, Goerge A. 1999. Human Communication research, Vol. 25 No. 4 , June 1999. International Communication Association. University of North Carolina at Charlotte \& State University of New York at Buffalo. pp. 589-603.

[7] Gbadamosi, K. T (2006): The Emergence of Motorcycle in Urban Transportation in Nigeria and its Implication on Traffic Safety. Centre for transport studies. Olabisi Onabanjo University, AgoIwoye.

[8] Jahn, Jody L. S. and Johansson, Catrin. The communicative constitution of adaptive capacity during Sweden's. University of Colorado, Boulder, Colorado, USA, Department of Media and Communication, Mid Sweden University, Sundsvall, Sweden.

[9] Lentfrom, Robert W. \& Loyola, Steven D. Brown. The following communication planned in addition contextual supports and barriers to career choice: asocial cognitive analysis report for a team researching, University of Maryland \& University Chicago, recipient Gail Hackett from Arizona State University.

[10] Salwan, Michael B. and Stacks, Don W. 1996. An Integrated Approach to Communication Theory and Reserch. Lawrence Erlbaum Associated, Publihers Mahwah, New jersey.

[11] McCroskey, James C. and Richmond, Virginia P. 1996. Human Communication Theory and research: traditions and Models. West virginia University, Publihers Mahwah, New jersey. pp. 233242.

[12] Mumby DL 1968. Transport: Selected Readings. Harmondsworth: Penguin.

[13] Odufuwa, B. O and Ademiluyi, I. A (2010), Transport Poverty and Deviant Driving Behaviour in Nigeria Intermediate Cities. Africa Journal of Social and Policy Studies. Vol. 3 No. 1 and 2. Pp. 144-149. Ogunsanya A. A. and Galtima, M. (1993) Motorcycle in Public Passenger Transport Service in Nigeria: A case Study of Yola Town, in Ikya, S. G. (ed) Urban Passenger Transportation in Nigeria. Heinemann Educational Books (Nig), Ibadan, pp 190-207. Oni, S. I (1999), Urban Transportation at State and Local Government Levels, A paper Presented at the Sixth International Conference on Competition In Land Passenger Transport, Rand burg, South Africa, September, 1999.

[14] Oni, S. I and Okanlawon, K. R (2010), "Transportation Education in Nigeria”, in Exploring the Multifaceted Dimensions in Exercise and Sports Psychology, Ikulayo, P. (ed), Olu-Akin Publishers, Ibadan, pp. 106-118. [11] Oni, S. I and Olagunju, Y. K (2010) "The Motorcycle Crash Charateristics in Lagos State, Nigeria. Journal of Environmental and Safety Vol 2, No. 1. January, pp 1-15. 
[15] Oni. S. I (2004): Development of Urban Transportation. In Chikolo, I. Ogunsanya, A. A. and Sumaila, A. G. (Eds). Perspectives on Urban Transportation in Nigeria. NITT. Zaria.

[16] Oyesiku, O. (2002): From womb to Tomb. 24th University Inaugural Lecture. Olabisi Onabanjo University Press, Ago Iwoye, Nigeria.

[17] Oyesiku, O. (2004): Policy Directions in Urban Transportation. In Chikolo, I. Ogunsanya, A. A. and Sumaila, A. G. (Eds). Perspectives on Urban Transportation in Nigeria. NITT. Zaria. pp. 171202.

[18] Oyesiku, O. O (2002) "Policy Framework for urban motorcycle public transport system in Nigeria Cities" In Xavier Godard and Innocent Fatonzon (eds) Urban mobility For All, Lisse: A. A. Balkema, pp. 255-261.

[19] Qian Hu. The transportation management technology with the understanding multiplexity of collaborative emergency management networks, American review of public administrations is articles explores the multiplex relationships among organizations within the context of emergency management. Be careful with their own an said work's is a networks, multiplicity, friendship networks, and emergency management networks. On assessment of regional vehicle operations in there are main conditions for integration success with a lot is delegation of theories on communication planning and transportation management technology in the assessment of regional vehicle operations.

[20] Watzlawick, Paul., Helmick, Janet and Jackson, Don D. Pragmatics of Human Communication; a Study of Interactional Patterns, pathologies, and Paradoxes. Mental Reaserch Institute Palo Alto, California. New York, London. WW Norton \& Company.

[21] Yodiansyah, Hefri. 2017. Access Literacy Media On Communication Planning, Vol. 11 No. 2, June 2017. JIT; Jurnal Ilmu Terapan. Kopertis 10. Padang, ISSN: 1979-9292, E-ISSN: 2460-5611, https://doi.org/10.22216/jit.2017.v11i2.966. pp. 128-155.

\footnotetext{
*Corresponding author.

E-mail address: hefri.yordiansyah@ gmail.com/n.yuzalmi@ gmail.com/irsyadi.zain@ gmail.com

Author ID Portal Sinta Ristekdikti address: http://sinta2.ristekdikti.go.id/author/?mod=login; Sinta Id1), 6172991; Sinta id2), 6199815; Sinta id3), 6111341.
} 